\title{
GOING BEYOND TECHNOLOGICAL AFFORDANCES - ASSESSING ORGANIZATIONAL AND SOCIO-INTERACTIONAL AFFORDANCES
}

\author{
Kirsi Lainema ${ }^{1}$, Timo Lainema ${ }^{2}$, Raija Hämäläinen ${ }^{1}$ and Kirsi Heinonen ${ }^{1}$ \\ ${ }^{1}$ University of Jyväskylä, Finland \\ ${ }^{2}$ University of Turku, Finland
}

\begin{abstract}
Analysis of the applicability of a learning technology requires evaluating how the affordances of the technology respond to the users' needs. We examine affordances of a digital learning environment. We concentrate on organizational and socio-interactional affordances, which are based on technological affordances. The analysis shows how organizational and socio-interactional affordances emerge from the use of technological affordances. We offer an analytical understanding of the dynamics of various kinds of affordances and how they can be assessed to help educators to better understand how the learning process and the use of affordances can be facilitated and supported.
\end{abstract}

\section{KEYWORDS}

Organizational Affordances, Socio-Interactional Affordances, Computer-Based Learning

\section{INTRODUCTION}

The use of different learning technologies has rapidly increased on all educational fields, and along it, the study of affordances has gained momentum. The term 'affordance' was first coined by Gibson (1979, cited in Salomon, 1993), who used it to refer to the functional properties that determine the possible utility of an object or an environment. Affordances can be defined as action possibilities latent in the object (the learning environment) and dependent on the capabilities of the agent (learners) (Antonenko, Dawson \& Sahay, 2017). Affordances are more than just technical properties of an object, as they represent an action potential that needs to be met with respective capabilities of the user. A chair represents an everyday case in point. Chair's affordance is sit-ability, and it can be used for that purpose by a person who wants and is able to sit. In the context of a digital learning environment affordances include, e.g. view-ability, read-ability, and move-ability.

It is apparent that the technological aspects of digital learning environments dominate the current discussion, and the socio-interactional and organizational aspects receive less attention. We find, however, that it is mandatory to gauge into the interplay of the three types of affordances in more detail to develop a better understanding on how digital learning environments can be designed and applied to empower students to utilize their full capacity and all available resources. In doing so we also re-consider the notion of affordances as resources for computer-supported collaborative learning (CSCL) (Koschmann, 2012).

Analysis of the applicability and usefulness of a technology requires evaluating how the affordances of the technology respond to the users' needs and abilities (Antonenko, Dawson \& Sahay, 2017). Some examples of the affordances of social software tools are, for example, connectivity and social rapport, and collaborative information discovery and sharing (McLoughlin \& Lee, 2007). As an example of the first, technology-based environments support networks of people and facilitate connections between them. These kinds of environments are representatives of what Gee (2004) calls affinity spaces, where people acquire both social and communicative skills, and at the same time become engaged in the participatory culture of the environment. In these spaces, learners engage in informal learning, and creative, expressive forms of behavior and identity seeking, while developing a range of digital literacies. One cannot assume that just because social software entails certain affordances, it is all that is required for effective learning. Careful planning and a thorough understanding of the dynamics of these affordances are mandatory (McLoughlin 
\& Lee, 2007). An explicit approach to identifying technological affordances of e-learning tools and the affordance requirements of e-learning tasks should be used to scaffold the learning design process (Bower, 2008).

Traditionally, socio-culturally oriented research perspective on CSCL is closely associated with affordances (Moeate et. al., 2019). The focus is on group learning and how the social context in which collaboration emerges. This presentation is in line with the notion from Arvaja, Salovaara, Häkkinen and Järvelä (2007), who view collaboration as shared knowledge construction, where participants not only cumulatively share knowledge together, but where the knowledge construction is jointly built on others' ideas and thoughts (see also Mercer, 2010). The aim is that the activities of the collaborative group are not a collection of individual activities, but rather interdependent group processes (e.g. interactions) pursuing a shared conception of a problem (Roschelle \& Teasley, 1995). Furthermore, these shared processes are mediated by the community and social context in which the group work takes place (Stahl, 2012).

We argue that the continually increasing amount of resources allocated to the development of educational simulations by educational institutions calls for in-depth studies of affordances. We need to understand how simulations and games can be designed in pedagogically sound ways to empower the users to acknowledge the affordances embedded in these environments. Furthermore, we believe that the use the students make of online learning environments will very much depend on their attitudes towards these environments and on the perceived affordances. This is also the motivation of our study.

\section{AFFORDANCES}

Research of affordances is interdisciplinary, and while it originates from Ecological Psychology (Gibson, 1979), it has found application in Education (Kirschner, 2002), Information Systems, Organization Studies, and Management disciplines (Pozzi, Pigni \& Vitari, 2013). We examine affordances of a digital learning environment perceived and utilized by dispersed student teams. The novelty of our study lies in incorporating not only the technological aspects of affordances in our analysis, but also including the socio-interactional and organizational dimensions to our treatment. The use of socio-interactional and organizational affordances plays a key role in how these technologies can be made to work.

As learners engage in a technology-based learning environment they perceive "affordances" of objects, defined as the acts or behaviors that are afforded or permitted by an object, place, or event (Michaels and Carello, 1981, p. 17). Affordances are, thus, different from properties of objects. Affordances are perceptions on what we can do with the properties of objects. Although affordances can be perceived as preconditions for an activity, they do not imply that a specific activity will occur (Greeno 1994). As affordances are just potentials for action, taking benefit of them requires that they are triggered (Volkoff and Strong 2013) or actualized (Strong et al. 2014). Pozzi, Pigni \& Vitari (2013) recognize four steps in the application of affordances: an affordance exists; the user perceives the affordance; the user actualizes the affordance; and finally, the actualization leads to affordance effect. In our study we focus predominantly on affordances as the doings that the actors engage in. In doing so we follow Majchrzak and Markus (2012), who note that affordances are best phrased in terms of action verbs or gerunds, such as "share knowledge" or "information sharing" and involve technological, organizational and social dimensions.

Another novel aspect in our study is that while the overall learning environment is the same for all teams, the team members utilize and combine the various affordances differently and complementarily. Their particular combinations may depend, for example, on the availability and functionality of the technologies, the participants' personal preferences or a mutual team agreement, or the team members' technical skills. Consequently, the teams get organized differently, and utilize and develop different practices to organize the team task and to communicate in the teams. All this has an impact on what is done, when, by whom, and with what kinds of outcomes. This further emphasizes the importance of going beyond the mere technical affordances and assess how the available affordances are organized, taken benefit of, and affect interaction.

\subsection{Technological Affordances}

The concept of technology affordance refers to an action potential - what an individual or organization with a particular purpose can do with technology (Majchrzak and Markus, 2012). For example, essential for analyzing the potential utility of educational technologies is seen the issue of categorizing technological 
affordances and aligning them with the abilities they afford the users of the technology (Antonenko, Dawson \& Sahay, 2017).

Bower (2008) makes an effort to describe affordances based on their physical characteristics, emphasizing their functionality. He proposes a methodology for matching the affordance requirements of learning tasks with the technological affordances of ICT tools. Bower's affordance classification system includes 11 different areas of technological affordances (see Table 1). In this paper we focus predominantly in the actual action possibilities perceived and utilized by the users (usability). Moreover, we are interested in analyzing the dynamics of technological, organizational and socio-interactional affordances, and their combinations as reported by the learners. Expanding our treatment from predominantly technological view allows for appreciating the interplay between and among the various types of affordances.

\subsection{Organizational Affordances}

With organizational affordances we refer to the practices of organizing that the actors produce in situ and take advantage of. The organizational dimension of social learning environments is often overlooked and treated as a taken-for-granted element. Our analysis shows, however, that the organizational dimension is, in fact, quite crucial for the team's functioning and the outcomes of the learning exercise. Thus, the way the teamwork is organized has a fundamental influence on what is learned during the exercise.

At first glance, organizational affordances may seem a fuzzy category, as it sometimes is difficult to discern which actions can, in fact, be understood as organizing. In our context organizing is regarded as assembling the available resources to attain order, structure and organizational objectives (BusinessDictionary, 2019). In addition to assembling resources to attain certain objectives, organizational affordances entail also managing the process and the participants. This is accomplished through communication, so organizational and socio-interactional affordances are closely linked and intertwined.

\subsection{Socio-Interactional Affordances}

Socio-interactional affordances comprise of the various synchronous and asynchronous forms of communicating: emailing, chatting on Skype or Facebook, and on-line talk using VoIP-applications. We found that the participants employed different interactional affordances depending on the situation at hand, and more importantly, depending on their team role.

\section{CASE LEARNING ENVIRONMENT, DATA AND ANALYSIS}

The study was conducted with higher education business students $(\mathrm{N}=207)$ from 10 universities ( 2 from Austria, Belgium, China, Estonia, 3 from Finland, New Zealand and USA). These students represented 38 different nationalities (the biggest ones being Finnish 52 students, New Zealandian 52, Austrian 29, Belgian 15, and Chinese 14). Participants were undergraduate students. The simulation game is a clock-driven business simulation, in which the game processes evolve hour by hour. The participants need to make decisions continuously, and not as batches as is the normal case in business simulations. The clock-driven nature of the simulation requires that participants run their simulation companies in synchronous collaboration. As the teams of participants were quite big, the teams worked in shifts. It was recommended that during the 14 hour simulation day each team had at least 3-4 participants online all the time. Shift work was natural also from the point of view of the geographical dispersion of the participants - from New Zealand to New York, USA.

The students were placed in teams of 10-13 members (18 teams in total). The teams had a real-time view to their simulation companies through a remote connection. This means that all the team members online saw the same simulation screen on the remote computer, and all the team members were able to make decisions in the simulation. The members used real-time communication in their internal team communication. This was done mostly by using Voice over Internet Protocol (Skype), but some teams also collaborated using chat and email. The students were assigned to write two reflective essays in English: the first directly after the first gaming session, and the second after the final gaming session. We focus on analysing the first essays. 


\subsection{Data Collection}

Out of the 207 participating students, 177 returned the essay after the first simulation session. Students were asked to reflect on teamwork, roles, tasks and virtual collaboration and communication.

\subsection{Analysis}

Data were analyzed with qualitative content analysis using data-driven analysis (e.g. Krippendorf 2014). The data analysis process was inductive, allowing for the analytical categories to emerge from the data rather than pursuing to fit the data into existing categories. The question that was posed to the data was: what issues/elements in the gaming exercise enabled or hindered the team task? Most students were quite talkative, and wrote lengthy descriptions of their gaming experience. While doing so, they explained how their team got organized, and how they worked as a team. The use of technologies played a key role, and the technology was put in use by means of communication and collaboration.

The analysis entailed careful close reading of the data in iterative rounds. First, two of the authors conducted the qualitative analysis independently. During the reading the observations were summed up and coded in categories of different types of "doings". The findings were mutually discussed, and the analytical categories were further refined to better respond to the aim of the study. Further analyses helped sharpen the focus and yielded in three main categories of action potentials: technological, socio-interactional, and organizational affordances. The analysis details how participants to the learning simulation perceived and seized the various affordances in the learning environment, and how these were intertwined and influenced by each other.

The simulation game exercise consists of different phases and tasks. First, the participants need to familiarize themselves individually with the relevant materials and finalize the course pre-assignments. Then, the team members need to get acquainted with each other, and get the team organized. This is the time point when the team work factually begins, and when the participants start to interact with each other and with the learning environment and its elements. The simulation game is run on two separate days ( 2 weeks in between), and there are team assignments and individual assignments between the gaming days and after the final gaming day. Our analysis focuses on two sets of activities: activities before the first simulation exercise and activities during the first simulation exercise. This type of an analysis allows for gauging into the specific nature of affordances perceived and employed at each stage. In the next section we present the findings of our analysis.

\section{FINDINGS}

We report on the preliminary findings of our analysis on a general level. Already this preliminary analysis brings forth important observations. As expected, the three types of affordances seem to be intertwined and co-dependent. Hence, it is arbitrary to forcefully try to separate them from each other. For clarity, we present the findings of our analysis categorized under technological, organizational, and socio-interactional affordances.

\subsection{Technological Affordances}

Many of the technological affordances were, in fact, related to technological prerequisites. When working in a digital learning environment some basic requirements need to be met before the gaming can take place. For example, in Bower's (2008; see table 1 below) classification, Media affordances and Spatial affordances are normally prerequisites for a functional e-learning system. Teams selected different communication technologies for different purposes and different tasks. E.g., email was found clumsy during gaming, whereas it was deemed an efficient form of disseminating information before gaming. In teams where the members shared more personal information, applications like Facebook were used more often than in teams with less personal information sharing. The choice and use of communication technologies played a key role also in how the teams got organized. In teams with poor audio connection, chat or text messaging was the 
technology of choice. Some teams moved from audio to chat particularly due to problems with audio. Group discussion in audio were sometimes deemed chaotic due to simultaneous talk and delays in broadcast. On the other hand, some teams were successful in using audio, and found it very useful and convenient. The gaming exercise required simultaneous use of multiple technologies, and some teams quickly saw which combinations were most fruitful. Table 1 illustrates how the different technological affordances (Bower, 2008) show in the essays.

Table 1. Identified Technological affordances (adapted from Bower, 2008)

\begin{tabular}{|c|c|c|}
\hline $\begin{array}{l}\text { Technical } \\
\text { Affordance }\end{array}$ & Explanation & Example of how shows in student essays \\
\hline $\begin{array}{l}\text { Media } \\
\text { affordances }\end{array}$ & Input and output & $\begin{array}{l}\text { Being able to call and interact/discuss with other team } \\
\text { members while the game is running was what made the } \\
\text { game so alive and exciting (Team } 4) \text {. }\end{array}$ \\
\hline $\begin{array}{l}\text { Spatial } \\
\text { affordances }\end{array}$ & $\begin{array}{l}\text { Ability to resize elements, move } \\
\text { and place elements. }\end{array}$ & \\
\hline $\begin{array}{l}\text { Temporal } \\
\text { affordances }\end{array}$ & $\begin{array}{l}\text { Access anytime anywhere, } \\
\text { synchronous versus } \\
\text { asynchronous. }\end{array}$ & $\begin{array}{l}\text { I decided to join my team in the morning, at } 05: 00 \\
\text { UTC }+0 . \text { At this time a few of my team members already } \\
\text { worked on... (Team } 12) .\end{array}$ \\
\hline $\begin{array}{l}\text { Navigation } \\
\text { affordances }\end{array}$ & $\begin{array}{l}\text { Capacity to browse to other } \\
\text { sections of a resource and move } \\
\text { back/forward. }\end{array}$ & $\begin{array}{l}\text {... a chat with all the team members inside the programme } \\
\text { can help us to converse easier because now we had to } \\
\text { handle two programmes at the same time (Team } 3 \text { ). }\end{array}$ \\
\hline $\begin{array}{l}\text { Emphasis } \\
\text { affordances }\end{array}$ & $\begin{array}{l}\text { Capacity to highlight aspects of } \\
\text { resources. }\end{array}$ & $\begin{array}{l}\text {...we started tutoring new people by explaining everything } \\
\text { that we were doing loudly and showing it directly in the } \\
\text { simulation (Team } 3) \text {. }\end{array}$ \\
\hline $\begin{array}{l}\text { Synthesis } \\
\text { affordances }\end{array}$ & $\begin{array}{l}\text { Capacity to combine multiple } \\
\text { tools together to create a mixed } \\
\text { media environment. }\end{array}$ & $\begin{array}{l}\text { We mainly discussed by writing but also had Skype } \\
\text { call(s)... I prefer not to speak English so writing was ideal } \\
\text { for me (Team 1) }\end{array}$ \\
\hline $\begin{array}{l}\text { Access-control } \\
\text { affordances }\end{array}$ & $\begin{array}{l}\text { Capacity to allow or deny who } \\
\text { can operate, capacity to support } \\
\text { one-one/many-many } \\
\text { contributions. }\end{array}$ & $\begin{array}{l}\text { I ... expected that production, inventory and sales } \\
\text { would've been spread into different pages making it all } \\
\text { faster to control and not ... waiting someone to finish their } \\
\text { own tasks.(Team } 1) \text {. }\end{array}$ \\
\hline $\begin{array}{l}\text { Technical } \\
\text { affordances }\end{array}$ & $\begin{array}{l}\text { Capacity to be used on various } \\
\text { platforms, ability to adapt to } \\
\text { bandwidth, efficiency of tools. }\end{array}$ & $\begin{array}{l}\text { In my shift was one girl who had a bad internet connection } \\
\text { and therefore she couldn't take part in our Skype- } \\
\text { conference (Team 3). }\end{array}$ \\
\hline Usability & $\begin{array}{l}\text { Intuitiveness, ease of } \\
\text { manipulating a tool. }\end{array}$ & The game was easy to get into... (Team 2). \\
\hline Aesthetics & Appearance of interface. & \\
\hline Reliability & Robustness. & $\begin{array}{l}\text { If the game cut out it would automatically re-connect... } \\
\text { (Team } 4) \text {. }\end{array}$ \\
\hline
\end{tabular}

\subsection{Organizational Affordances}

Much of the organizational work in the simulation gaming exercise was related to securing the availability and timely delivery of resources. Before the simulation exercise the teams needed to get organized. Shift planning was needed to ensure that there were enough team members online, that is, a minimum of 3 people at any given time. Teams also needed to decide how to deal with the responsibilities and roles in the game. It was suggested in the game materials that teams choose designated persons to at least three roles: purchasing raw materials, managing the production, and making sales offers and deliveries to customers. In some teams one of the team members took the initiative to send out a Doodle poll to let the team members indicate when they were available and which role they felt most comfortable with. Others used different excel charts or sent emails to each other. Some teams made plans only for the shifts, and not the roles.

In general, I believe our team was overall very unbalanced, as the roles were not clearly defined,... and ultimately everybody had something to say to whatever was to be performed as company activity (production, offers, sales,...). (Team 12)

However, it appeared that the roles needed not to be very precise and carefully planned for the team to function well. I think we had very clear responsibilities and everyone did their best and we supported each other and helped when needed. Of course, because we didn't have a business strategy at all, everything we did was intuitive, so our functions or ways to do things were built up just in time in the game. (Team 3) 
Communication and organization for the teamwork went hand in hand, and teams with multiple communicative occasions and versatile organizational tools (Doodle, excel charts, explicit goal setting) were better prepared and oriented to the simulation exercise. In some of the teams one or two team members even contacted each team member individually to negotiate a suitable shift and role, which was regarded as a welcomed practice.

Firstly, the communication and enthusiasm of my team was beyond impeccable in my opinion. As soon as the team lists were released, I had emails from most of the members in my group by the end of that day. (Team 3)

Some teams had clear leadership, either by self-selection or by mutual agreement. In these teams the leadership was more established and visible, and acknowledged by most team members. Leadership was partly an issue of controversy, as some participants had reservations for strong leadership. In general, however, teams with clear leadership reported more satisfaction and better results.

...I found the team to be relatively effective, although lacking a leader figure. Because of this, I stepped in and created a Facebook group in which we could communicate quicker than that over email. This was effective, and some team members created a roster where it was outlined what hours each individual was online for, and their duty during that given time. (Team 15)

In the next table, the categories of organizational affordances are presented. Our analysis yielded in three types of organizational affordances or practices, which are partly overlapping. The categories are: organizing, managing, and leading. In the following table we present the activities in each category.

Table 2. Identified Organizational affordances

\begin{tabular}{|c|c|c|}
\hline Organizing & Managing & Leading \\
\hline $\begin{array}{l}\text { Organizing shifts and tasks } \\
\text { (Doodle poll, excel chart) }\end{array}$ & Managing one's own task & $\begin{array}{l}\text { Pointing out critical areas and } \\
\text { initiating discussion }\end{array}$ \\
\hline $\begin{array}{l}\text { Re-organizing shifts and tasks } \\
\text { during gaming }\end{array}$ & $\begin{array}{l}\text { "Feeling the pulse"- hearing how others } \\
\text { are doing }\end{array}$ & $\begin{array}{l}\text { Setting an agenda for team } \\
\text { talks }\end{array}$ \\
\hline $\begin{array}{l}\text { Gathering information from the } \\
\text { team and using it to securing } \\
\text { and re-arranging resources }\end{array}$ & Suggesting what to do next - giving orders & $\begin{array}{l}\text { Making projections based on } \\
\text { the available data }\end{array}$ \\
\hline \multirow[t]{2}{*}{ Ensuring all areas are covered } & $\begin{array}{l}\text { Compromising through team talk - } \\
\text { finding middle ground }\end{array}$ & $\begin{array}{l}\text { Discussing and suggesting } \\
\text { strategy }\end{array}$ \\
\hline & Managing contacts to collaborative teams & Announcing decisions \\
\hline
\end{tabular}

The most important organizational work before the gaming exercise was to organize the shifts. Teams with sufficient amount of participants online at any given time were most satisfied with the team work. The teams with too few people online found it stressful and chaotic to try to run the simulation company. Our analysis illustrates how organizational affordances are made possible by employing technological affordances, which, in turn, are prerequisites for the whole learning exercise. It is the dynamics of the various kinds of affordances and their combinations in the digital learning environment that create the potential for learning.

\subsection{Socio-Interactional Affordances}

Some interactional aspects in the gaming exercise were, similarly to technological affordances, prerequisites of communication. For example, gaining access to the relevant information was imperative as without it the team members could not function properly. Another important aspect was that the needed information was available at the right time. This, in turn, was closely linked with the technology in use. Many teams found email and Skype chat clumsy for rapid communication and chose synchronous VOIP-solutions for talking about pressing issues. The analysis revealed that the socio-interactional affordances fall into four distinctive categories: observing, participating, facilitating, and chairing. Some affordances can be placed in multiple categories, but the main difference between the affordances is the level of input and activity.

In alternating between technologies and channels appropriately, different kinds of communicative contributions are relevant for the team task. However, if everyone was disseminating information and nobody was drawing conclusions, the team task and its accomplishment would be compromised. A balanced participation and contribution brings results and increases the team's satisfaction to the team's functioning.

I got so enthusiastic that I watched the game even later in my course because I was so excited about the project. Moreover, I am glad to be a part of such project because it teaches us more than any book about cross- cultural and virtual communication. (Team 12) 
Table 3. Identified Socio-interactional affordances

\begin{tabular}{|c|c|c|c|}
\hline Observing & Participating & Facilitating & Chairing \\
\hline \multirow[t]{7}{*}{$\begin{array}{l}\text { Listening to what } \\
\text { others are saying }\end{array}$} & $\begin{array}{l}\text { Listening to what others are } \\
\text { saying }\end{array}$ & $\begin{array}{l}\text { Listening to what others are } \\
\text { saying }\end{array}$ & $\begin{array}{l}\text { Listening to what others are } \\
\text { saying }\end{array}$ \\
\hline & $\begin{array}{l}\text { Acknowledging what others } \\
\text { are saying }\end{array}$ & Encouraging others to speak & Drawing conclusions \\
\hline & Listening, stepping back & Facilitating the discussion & Making suggestions \\
\hline & $\begin{array}{l}\text { Responding to what others are } \\
\text { saying }\end{array}$ & $\begin{array}{l}\text { Repeating what has been } \\
\text { said }\end{array}$ & Announcing decisions \\
\hline & Disseminating information & Disseminating information & Disseminating information \\
\hline & Giving feedback & Giving feedback & Giving feedback \\
\hline & & $\begin{array}{l}\text { Negotiating, finding middle } \\
\text { ground }\end{array}$ & $\begin{array}{l}\text { Negotiating, finding middle } \\
\text { ground }\end{array}$ \\
\hline
\end{tabular}

When designing learning environments it is important to acknowledge the role of technological affordances as enablers or hindrances to the learning exercise. The technological affordances can be designed in ways that encourage and facilitate team work and interaction, and support the development of organizational skills.

\section{CONCLUSION}

An abundance of affordances does not mean that they will be perceived or utilized by the actors. As Kaptelinin and Nardi (2006) note, a technology must improve interactions between the individual and the environment to be useful. In the case at hand, operating in the learning environment required coordinated action to accomplish the team task, that is managing the virtual simulation manufacturing companies successfully. In their essays the participants described how they perceived and utilized the various affordances embedded in the learning environment, and to what kinds of outcomes. The participants evaluated their team success not only in terms of how well the team performed, but also how well the team worked together and what they learned. The latter, in our opinion, gives an even better indication of how affordances and their use is connected to learning.

Teams chose partly different combinations of communication technology. Before game most teams resorted to asynchronous communication technologies, such as email, to better control the flow of information and to have a record of all communication. During the simulation game synchronous communication via Skype was found most appropriate by most teams. However, some teams continued to rely on chat and not talk on-line. For some teams this choice was motivated by the team members' reluctance to speak English. Delays in communication lead, however, to misunderstandings, missing information, and confusion. It was apparent that the teams with most self-reported motivation and initial success made changes in their use of technology and communication tool according to what took place in the game. These teams also adapted their organization according to the situation and used appropriate organizational practices to pursue the best possible outcome for the team at any given situation. This is quite an important observation, since flexibility, adaptivity and the accommodation of available resources and affordances to the task at hand are some of the most important skills needed not only in learning activities, but on all areas of life.

Teams with less self-reported motivation and successful outcomes had less occasions of communication before and during the gaming exercise. These teams also resorted more to asynchronous communication during gaming, such as chat and email. Less satisfied teams seemed to be unable to adjust their team effort and to correct the down fall spiral. We assert that student-centered learning requires that the learning environment encourages and empowers the students to search for information, try different tactics and strategies, test ideas and create new knowledge. These potentials need, however, be carefully and purposefully designed and integrated in the learning environment, as they do not miraculously appear there without purposeful planning and effort. Consequently, we find that it is of utmost importance to study affordances in more depth, and to learn how they can be embedded in the learning environments to enhance and empower learning.

...this online simulation definitely surpassed by expectation of how much I would learn. Learning how to compromise, learning how to negotiate, learning how to speak up, learning how to manage, and most importantly, learning how to work as a collaborative team through an online virtual world. (Team 4) 
Our study illustrates that while the learning environment contained an abundance of affordances, available for all teams, the teams perceived them differently and employed them differently. Not all affordances were employed by all teams, which lead to varying outcomes and different perceptions of the success of the team work. A more thorough understanding of the dynamics of affordances can to design accessible and learning environments, and to help educators to better understand how the learning process and the use of affordances can be facilitated and supported.

\section{REFERENCES}

Arvaja, M., Salovaara, H., Häkkinen, P., \& Järvelä, S. (2007). Combining individual and group-level perspectives for studying collaborative knowledge construction in context. Learning and Instruction, Vol. 17, No. 4, pp. 448-459.

Antonenko, P., Dawson, K., \& Sahay, S. (2017). A framework for aligning needs, abilities and affordances to inform design and practice of educational technologies. British Journal of Educational Technology, Vol. 48, No. 4, pp. 916-927.

Bower, M. (2008). Affordance analysis-matching learning tasks with learning technologies. Educational Media International, Vol. 45, No. 1, pp. 3-15.

BusinessDirectory (2019). Online: http://www.businessdictionary.com/definition/organizing.html. June 27, 2019.

Gee, J. P. (2004) Situated Language and Learning: a critique of traditional schooling. London: Routledge.

Gibson, J. J. (1979). The ecological approach to visual perception. Boston: Houghton Mifflin.

Greeno, J. G. (1994). Gibson's affordances. Psychological Review, Vol. 101, No. 2, pp. 336-342.

Kirschner, P. A. (2002). Can we support CCSL? Educational, social and technological affordances. In Kirschner (ed.) Three worlds of CSCL: Can we support CSCL? Heerlen: Open Universiteit Nederland, pp. 7-47.

Kaptelinin, V. \& Nardi, B. (2006). Acting with technology: activity theory and interaction design. Cambridge: MIT Press.

Koschmann, T. (2012). CSCL: Theory and practice of an emerging paradigm. Routledge.

Krippendorff, K. (2004). Content Analysis. An Introduction to Its Methodology. Sage Publications, Thousand Oaks, California. Second Edition

Majchrzak, A., \& Markus, M. L. (2012). Technology affordances and constraints in management information systems (MIS). Encyclopedia of Management Theory, (Ed: E. Kessler), Sage Publications.

McLoughlin \& Lee (2007). Social software and participatory learning: Pedagogical choices with technology affordances in the Web 2.0 era. Proceedings ascilite, Singapore. Online: https://researchbank.acu.edu.au/cgi/viewcontent.cgi?article=3049\&context=fea_pub

Mercer, N. (2010). The analysis of classroom talk: Methods and methodologies. The British Journal of Educational Psychology, Vol. 80, pp. 1-14.

Michaels, C. F. and C. Carello (1981) Direct Perception. Englewood Cliffs, NJ: Prentice Hall.

Moate, J., Hulse, B., Jahnke, H., \& Owens, A. (2019). Exploring the material mediation of dialogic space-A qualitative analysis of professional learning in initial teacher education based on reflective sketchbooks. Thinking Skills and Creativity, Vol. 31, pp. 167-178.

Pozzi, G., Pigni, F., \& Vitari, C. (2013). Affordance theory in the IS discipline: A review and synthesis of the literature. In AMCIS 2014 Proceedings.

Roschelle, J., \& Teasley, S. (1995). The construction of shared knowledge in collaborative problem solving. In C. O’Malley (Ed.), Computer supported collaborative learning (pp. 69-97). NATO ASO Series F: Computer and System Sciences, Vol. 128. Berlin: Springer-Verlag.

Salomon, G. (1993). No distribution without individuals' cognition: A dynamic interactional view. Distributed cognitions: Psychological and educational considerations, pp. 111-138.

Stahl, G. (2012). Ethnomethodologically informed. International Journal of Computer-Supported Collaborative Learning, Vol. 7, No. 1, pp. 1-10.

Strong, D. M., Johnson, S. A., Tulu, B., Trudel, J., Volkoff, O., Pelletier, L. R., Bar-On, I., and Garber, L. (2014). A Theory of Organization-EHR Affordance Actualization, Journal of the Association for Information Systems, Vol. 15, No. 2.

Volkoff, O., and Strong, D. M. (2013). Critical Realism and Affordances: Theorizing It-Associated Organizational Change Processes, MIS Quarterly, Vol. 37, No. 3, pp. 819-834. 